\title{
Rosenberg Self-Esteem Scale
}

National Cancer Institute

\section{Source}

National Cancer Institute. Rosenberg Self-Esteem Scale. NCI Thesaurus. Code C123318.

A 10-item scale for the subjective scoring of a person's self esteem, developed by Dr. Morris Rosenberg, that ranges from strongly agree to strongly disagree. Five of the items have positively worded statements and five have negatively worded statements. 